\title{
3D-PRINTING-ASSISTED FABRICATION OF CHITOSAN SCAFFOLDS FROM DIFFERENT SOURCES AND CROSS-LINKERS FOR DENTAL TISSUE ENGINEERING
}

\author{
M. EzEldeen ${ }^{1,2, *}$, J. $\operatorname{Loos}^{3}$, Z. Mousavi Nejad ${ }^{1,4}$, M. Cristaldi ${ }^{1,5}$, D. Murgia ${ }^{1,5}$, A. Braem ${ }^{3, \S}$ and R. Jacobs ${ }^{1,6, \S}$ \\ ${ }^{1}$ OMFS IMPATH Research Group, Faculty of Medicine, Department of Imaging and Pathology, \\ KU Leuven and Oral and Maxillofacial Surgery, University Hospitals Leuven, Kapucijnenvoer 33, \\ 3000 Leuven, Belgium \\ ${ }^{2}$ Department of Oral Health Sciences, KU Leuven and Paediatric Dentistry and Special Dental Care, \\ University Hospitals Leuven, Kapucijnenvoer 33, 3000 Leuven, Belgium \\ ${ }^{3}$ KU Leuven Department of Materials Engineering, Biomaterials and Tissue Engineering research group, \\ Kasteelpark Arenberg 44, 3001 Leuven, Belgium \\ ${ }^{4}$ Biomaterials research group, Department of Nanotechnology and Advance Materials, \\ Materials and Energy Research Centre, P.O. box: 31787-316, Karaj, Alborz, Iran \\ ${ }^{5}$ Department of Surgical, Oncological and Oral Sciences, University of Palermo, Via Liborio Giuffrè 5, \\ 90127 Palermo, Italy \\ ${ }^{6}$ Department of Dental Medicine, Karolinska Institute, Stockholm, Sweden \\ $\S$ These authors share senior authorship
}

\begin{abstract}
The aim of the present study was to fabricate and characterise chitosan scaffolds from animal and fungal sources, with or without gelatine as a co-polymer, and cross-linked to 3-glycidyloxyproply trimethoxysilane (GPTMS) or genipin for application in dental root tissue engineering.

Chitosan-based scaffolds were prepared by the emulsion freeze-drying technique. Scanning electron microscopy (SEM) and nano-focus computed tomography (nano-CT) were used to characterise scaffold microstructure. Chemical composition and cross-linking were evaluated by Fourier transform infraredattenuated total reflectance spectroscopy. Compression tests were performed to evaluate scaffold mechanical properties. Scaffold degradation was evaluated by gravimetric method and SEM. Scaffold bioactivity immersed in simulated body fluid was evaluated by SEM, with associated electron dispersive X-ray spectroscopy, and apatite formation was examined by X-ray diffraction. Finally, human dental pulp stem cells (hDPSCs) viability was evaluated.

The fabrication method used was successful in producing scaffolds with organised porosity. Chitosan source (animal vs. fungal), co-polymerisation with gelatine and cross-linking using GPTMS or genipin had a significant effect on scaffold properties and hDPSCs response. Chitosan-genipin (CS-GEN) scaffolds had the largest pore diameter, while the chitosan-gelatine-GPTMS (CS-GEL-GPTMS) scaffolds had the smallest. Animal chitosan-gelatine co-polymerisation increased scaffold compressive strength, while fungal chitosan scaffolds (fCS-GEL-GPTMS) had the fastest degradation rate, losing $80 \%$ of their weight by day 21 . Gelatine co-polymerisation and GPTMS cross-linking enhanced chitosan scaffolds bioactivity through the formation of an apatite layer as well as improved hDPSCs attachment and viability.

Tailored chitosan scaffolds with tuned properties and favourable hDPSCs response can be obtained for regenerative dentistry applications.
\end{abstract}

Keywords: Chitosan, fungal chitosan, dental pulp stem cells, dental tissue engineering.

*Address for correspondence: Mostafa EzEldeen, OMFS IMPATH Research Group, Faculty of Medicine, Department of Imaging and Pathology, KU Leuven and Oral and Maxillofacial Surgery, University Hospitals Leuven, Kapucijnenvoer 33, 3000 Leuven, Belgium.

Email: mostafa.ezeldeen@kuleuven.be

Copyright policy: This article is distributed in accordance with Creative Commons Attribution Licence (http://creativecommons.org/licenses/by-sa/4.0/). 


\section{List of Abbreviations}

ANOVA
CAD
CS-GEL-GPTMS
CS-GEN
CT
DA
ECM
EDX

FBS fCS-GEL-GPTMS

FD

FTIR-ATR

GPTMS

IQR

hDPSCs

MSC

MW

nano-CT

PBS

REPs

RGD

ROIs

SBF

SCAPS

SEM

SHED

TERM

XRD analysis GPTMS spectroscopy cells procedures acid papilla microscopy $\alpha \mathrm{MEM}$

analysis of variance computer-aided design chitosan-gelatine-GPTMS chitosan-genipin computed tomography degree of acetylation extracellular matrix energy-dispersive $\mathrm{X}$-ray

foetal bovine serum fungal chitosan-gelatine-

fractal dimension

Fourier transform infraredattenuated total reflectance

3-glycidyloxyproply trimethoxysilane interquartile range human dental pulp stem

mesenchymal stem cell molecular weight nano-focused CT phosphate-buffered saline regenerative endodontic arginine-glycine-aspartic

regions of interest simulating body fluid stem cells of the apical scanning electron stem cells from human exfoliated deciduous teeth tissue engineering and regenerative medicine X-ray diffraction Eagle's minimal essential medium alpha modification

\section{Introduction}

Oral tissues exhibit a slight regenerative capacity in response to decay, inflammation, trauma or resective surgeries. However, irreversible damage occurs frequently and a full recovery of the dentoalveolar structures is extremely challenging due to its complex anatomy (Albuquerque et al., 2014; Larsson et al., 2016). Recently, TERM has been explored for the replacement of injured and missing tissues, claiming promising results. Modern TERM has also opened new possibilities for regenerative dentistry. One of these is the application of REPs (Austah et al., 2018; EzEldeen et al., 2015; Meschi et al., 2018), which aim to repair/replace the inflamed/necrotic dentine/pulp complex to restore vascularisation, immune response, innervation and dentine deposition at a regulated rate mimicking that of the normal dentine/pulp complex (Albuquerque et al., 2014; Huang and Garcia-Godoy, 2014). REPs are of particular importance in the treatment of children's immature teeth suffering pulp necrosis to induce root development and subsequent maturation (Austah et al., 2018; EzEldeen et al., 2015; Meschi et al., 2018; Meschi et al., 2019). Other more common examples are guided periodontal and alveolar bone regeneration (Larsson et al., 2016). Nevertheless, current clinical protocols for dental tissue regeneration have been associated with highly variable outcomes (Larsson et al., 2016; Meschi et al., 2018; Meschi et al., 2019). Therefore, there is a need for clinically applicable biomaterial-supported dental tissue regeneration approaches.

TERM can be approached either in a cell-free or in a cell-based manner and the choice of the appropriate scaffold plays a crucial role in both approaches. Several natural and synthetic materials have been proposed as candidates for dento-alveolar tissue engineering (Galler and D'Souza, 2011; Galler et al., 2010). Chitosan has attracted much attention mainly because of its antimicrobial (Fakhri et al., 2020) and immunomodulatory properties (Caires et al., 2018; 2016), in addition to biocompatibility, biodegradability, low immunogenicity, gel-forming ability and osteoinductivity (Ceccarelli et al., 2017; Sharma et al., 2014). Chitosan is obtained by partial deacetylation of the insoluble chitin, which is a copolymer of $\mathrm{N}$-acetylglucosamine and glucosamine residues linked by $\beta$-1,4-glycosidic bonds (Nwe et al., 2009) as well as a natural polymer and structural element of the exoskeleton of crustaceans (such as crabs and shrimps), fungi or insects (Gathani and Raghavendra, 2016). The DA and MW of chitin can vary among members of the chitosan family (Liu et al., 2016). Chitosan's drawbacks are low strength, difficulty to control pore size, possible toxicity caused by chemical modifications and inconsistent behaviour with seeded cells (Gathani and Raghavendra, 2016). Moreover, chitosan isolated from crustaceans' shells can induce a possible allergic reaction in the human body. Therefore, chitosan preparation from fungal cell walls using fermentation technologies has been suggested as an alternative for the fabrication of scaffolds used in tissue engineering (Nwe et al., 2009). Fungal chitosan usually has a lower MW compared to animal chitosan, which is linked to a faster degradation rate and higher release of chitooligosaccharides (Nwe et al., 2009). Chitooligosaccharides have an important role in antimicrobial activity, immunomodulation, wound healing and subsequent tissue regeneration (Batista et al., 2018; Hamedi et al., 2018; Nwe et al., 2009). Therefore, the use of fungal chitosan might offer several advantages in the context of tissue engineering.

Chemical cross-linking agents such as glutaraldehyde and formaldehyde have been 
used to enhance the stability of chitosan scaffolds. However, the risk of toxicity upon release of nonreacted groups or after degradation has led to the interest in enzymatically or naturally derived crosslinking agents (Gao et al., 2014; Tonda-Turo et al., 2011). GPTMS contains an epoxy and silicon alkoxide functionality and can, therefore, be used as a coupling agent (Šapić et al., 2014). Genipin, found in Gardenia jasminoides fruit, is a natural cross-linking agent for macromolecules by binding amine groups between adjacent molecules (Gao et al., 2014). Genipin has interesting properties for dental applications, as it shows anti-inflammatory properties (Mi et al., 2005), and promotion of odontoblastic differentiation of human dental pulp cells (Kwon et al., 2015). Further, copolymerisation of chitosan with gelatine can enhance the biological response due to the presence of the integrin-binding RGD-like sequence in gelatine that will promote cellular attachment (Kumar et al., 2017).

The overall aim of the present study was to fabricate and characterise chitosan scaffolds from animal and fungal sources, with or without gelatine as a co-polymer and cross-linked to GPTMS or genipin for application in dental root tissue engineering.

\section{Materials and Methods}

\section{Chemicals and materials}

Two types of chitosan have been investigated for preparing the scaffolds: 1) chitosan of animal origin, i.e. $75-85 \%$ deacetylated chitin, having a medium MW of 190-310 kDa (448877, Sigma-Aldrich); 2) fungal chitosan derived from Aspergillus niger, i.e. 70-80\% deacetylated chitin having a low $\mathrm{MW}<30 \mathrm{kDa}(\mathrm{KION}$. CSH.PC, KIOnutrime CsG, KitoZyme s.a., Herstal, Belgium). Gelatine powder derived from porcine skin by acid-curing (type A) and having a gel strength of 300 g was used as additional polymer (G2500, SigmaAldrich). As cross-linking agents, genipin (powder, $>98 \%$ purity, G4796, Sigma-Aldrich; or > $98 \%$ purity, 6902-77-8, Challenge Bioproducts, Douliu, Taiwan) and 3-glycidyloxypropyl trimethoxysilane (GPTMS, liquid, > $98 \%$ purity, 440167, SigmaAldrich) were used. Acetic acid (> $99 \%$ purity, Chem-Lab NV, Zedelgem, Belgium) was used as a solvent for chitosan. PBS was purchased from Sigma-Aldrich. SBF medium was purchased from Heraeus, Weiss Technik, Belgium. hDPSCs were cultured in $\alpha$ MEM (Sigma-Aldrich) supplemented with $2 \mathrm{mmol} / \mathrm{L}$ L-glutamine (Sigma-Aldrich), $100 \mathrm{U} / \mathrm{mL}$ penicillin (Sigma-Aldrich), $100 \mu \mathrm{g} /$ $\mathrm{mL}$ streptomycin (Sigma-Aldrich) and $10 \%$ FBS (Gibco, Thermo Fisher Scientific). Serum-free MSC medium (MesenCult ${ }^{\mathrm{TM}}-\mathrm{ACF}$ Plus Medium, Stem Cell Technologies, Vancouver, Canada) was used for the metabolic activity assay. Fibronectin was purchased from Sigma-Aldrich and alamarBlue ${ }^{\mathrm{TM}}$ kit (alamarBlue ${ }^{\mathrm{TM}}$ cell viability reagent solution) from Thermo Fisher Scientific. Well plates used were 96well plate, TPP tissue culture plates (Sigma-Aldrich) and 96-well plate, Chimney well (Fluotrac ${ }^{\mathrm{TM}}$, Greiner, Austria).

\section{Scaffold synthesis and fabrication}

Chitosan-based scaffolds were prepared by the emulsion freeze-drying technique (Fig. 1). To this end, suitable size moulds were first designed using CAD software (3-Matic, Materialise, city?, Belgium) and then 3D printed using a polyjet printer (Objet350 Connex3, Stratasys, Rehovot, Israel). Next, chitosan was dissolved in an aqueous acetic acid solution to obtain a concentration of $1.5 \%(\mathrm{w} / \mathrm{v})$, heated at $40^{\circ} \mathrm{C}$ after mixing and kept under the fume hood for $3 \mathrm{~h}$ to remove most of the bubbles. Gelatine was added as an extra polymer to chitosan (for 2 experimental groups), with a chitosan/gelatine weight ratio of $1: 1$ (Cui et al., 2014; Sakai and Kawakami, 2007). After preparing the polymer solutions, GPTMS (chitosan/ GPTMS weight ratio of $1: 1$ ) (Chao, 2008) or genipin (animal chitosan/genipin weight ratio of $100: 1$ ) (Dimida et al., 2017; Lluch et al., 2009) were added as cross-linking agents to improve the mechanical properties and the chemical stability of the scaffolds (Sakai and Kawakami, 2007). As such, three different scaffold compositions were investigated, further referred to as chitosan-gelatine-GPTMS (CS-GELGPTMS), fungal chitosan-gelatine-GPTMS (fCSGEL-GPTMS) and chitosan-genipin (CS-GEN). After solution preparation, the precursor solutions were dispensed in the moulds and immediately placed in dry ice for directional freezing to obtain radially oriented pore structure. Finally, the filled moulds were freeze-dried for $24 \mathrm{~h}$ and demoulded to obtain the final scaffolds (Fig. 1).

\section{Scaffold characterisation \\ SEM}

To visualise the internal structure of the different chitosan scaffolds, cross-sections were prepared from cylindrical freeze-dried samples by immersing them in liquid nitrogen and cutting into pieces using a razor blade. Subsequently, samples were mounted on an aluminium sample holder using double-sided carbon tape and sputter coated with a $10 \mathrm{~nm}$-thick platinum layer under vacuum to achieve conductivity. Then, both cross-sections in longitudinal and transverse direction were observed by SEM (XL30 FEG, FEI Europe BV, Zaventum, Belgium). Imaging was conducted at an accelerating voltage of 5 or $10 \mathrm{kV}$, a spot size of 2 or 3 , a $10 \mathrm{~mm}$ working distance. A low accelerating voltage and a small spot size were used to avoid charging effects. The image processing software Fiji (Image J, National Institutes of Health) (Schindelin et al., 2012) was used to process the SEM images and determine the average pore size of the scaffolds by measuring the diameter of 5 pores in 5 different areas, for a total of 25 pores. 


\section{Nano-CT}

To non-destructively visualise the internal pore structure in a 3D fashion, fabricated scaffolds were investigated by X-ray CT. Acquisition of CT images was carried out using a submicrometric resolution CT device (Nanotom, GE Phoenix, Blomberg, Germany). Samples were positioned on a sample holder on the rotary table ensuring that the longitudinal axis coincided with the rotary axis. Scanning was performed over $360^{\circ}$ with a step size of $0.7^{\circ}$. All measurements were obtained using molybdenum target applying an operating voltage of $90 \mathrm{kV}$ and a current of $250 \mathrm{~mA}$ during a $16.5 \mathrm{~min}$ exposure time for one scan. No filters were used and an isotropic voxel size of $8.5 \mu \mathrm{m}$ could be reached. The projected radiographs were reconstructed in cross-sectional images using a commercial software package (Phoenix datosx, GE Phoenix, Wunstorf, Germany). The reconstructed nano-CT dataset was further visualised and analysed using a commercially available image analysis software (Amira, Thermo Fisher Scientific). Three ROIs $(2 \times 2 \times 1 \mathrm{~mm})$ were created from each image and were used to calculate the porosity and mean polymer strut thickness of the chitosan scaffolds.
As a measure for the 3D surface roughness of the scaffold struts, the FD was calculated from the nanoCT scans of the chitosan scaffolds. For very smooth surfaces, the FD is equal to a value of 2, while for extremely rough surfaces the FD will be approaching the limit value of 3 (Amancio et al., 2020; Militký and Bajzík, 2001). Three ROIs $(2 \times 2 \times 1 \mathrm{~mm})$ were created from each image for computational reasons. ROIs were binarised to obtain 3D models for the scaffold's struts. Then, the FD was calculated for each ROI and averaged to obtain the final score for each scaffold type (Amira, Thermo Fisher Scientific).

\section{FTIR-ATR}

To investigate the chemical composition and crosslinking process, fabricated chitosan scaffolds were analysed by FTIR-ATR (Vertex 70 with platinum ATR, Bruker) Chitosan starting materials and the various cross-linking agents (genipin, GPTMS and gelatine) were analysed as controls. All samples were prepared for analysis by grinding them to a fine powder with the aid of liquid nitrogen. Spectra were taken in the range 4,000-500 $\mathrm{cm}^{-1}$ at a resolution of $2 \mathrm{~cm}^{-1}$ and averaged over 64 scans.

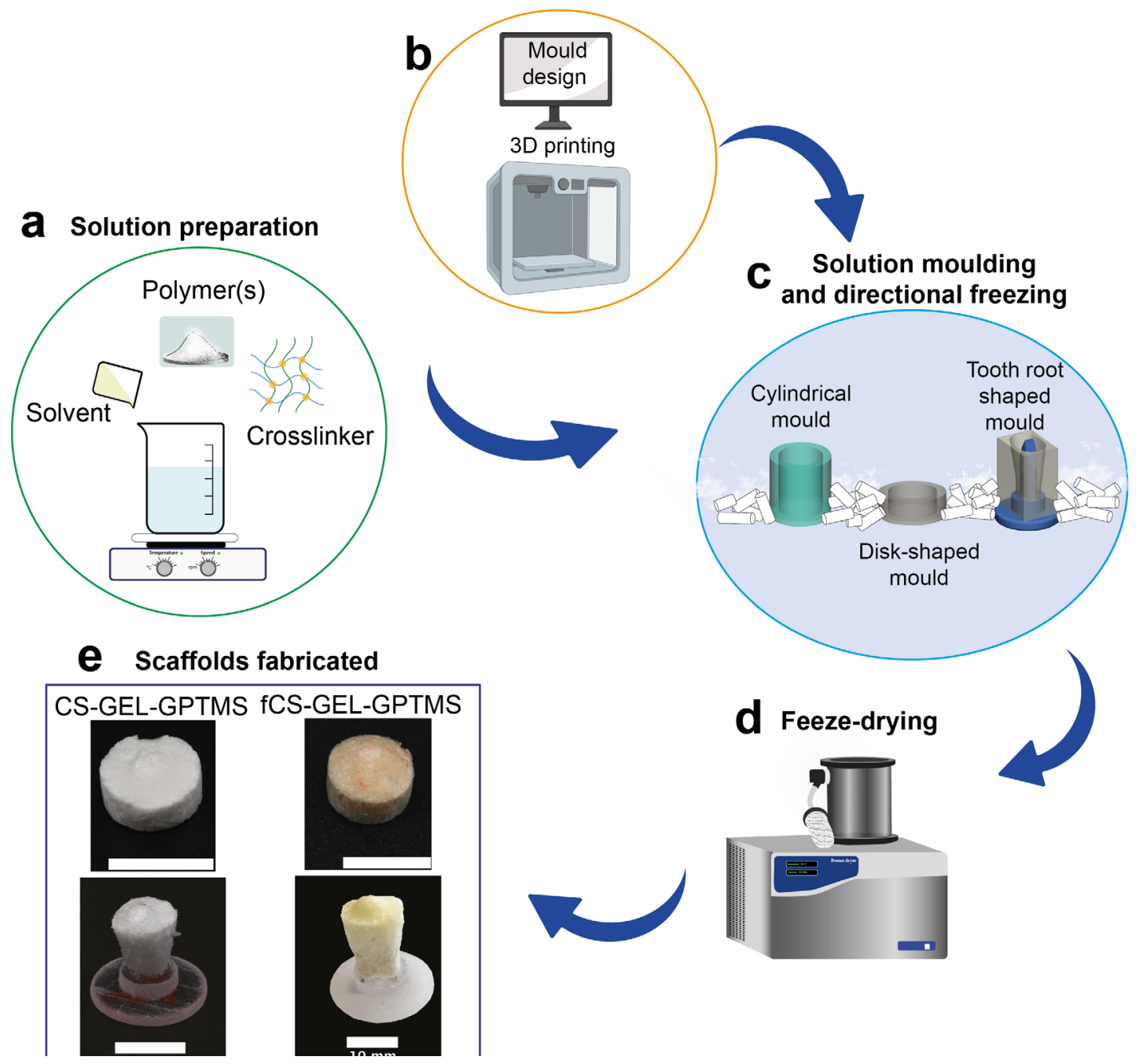

Fig. 1. Scaffold fabrication. (a) Polymer solution preparation; (b) CAD mould design and mould 3D-printing; (c) polymer moulding and directional freezing for different scaffold designs; (d) freeze-drying; (e) examples of scaffolds fabricated, scale bars: $10 \mathrm{~mm}$. 
Mechanical testing

To determine the load-bearing capacity of the chitosan scaffolds, compression tests were performed on cylindrical samples $(n=5)$ using a mechanical testing device (Instron 5567). A load cell of $1 \mathrm{kN}$ at a crosshead speed of $1 \mathrm{~mm} / \mathrm{min}$ was used. Time, load and extension were measured and captured using the Instron Bluehill software. The initial height and diameter of the samples were measured and used as input. The compressive modulus was calculated from the compressive stress-strain curve in the linear strain range, determined for each sample separately by plotting the compressive modulus in function of the strain. At least 4 samples were used to obtain reliable data.

\section{Scaffold degradation testing}

In vitro hydrolytic degradation tests were performed by incubating the scaffolds $(n=3$ per scaffold and time point) in PBS (pH 7.4) at $37^{\circ} \mathrm{C}$ under agitation for a predefined time interval. For these tests, disk-shaped (10 $\mathrm{mm}$ diameter and $5 \mathrm{~mm}$ height) samples were used in triplicate. To mimic human body conditions, a PBS buffer solution was used. This was prepared by dissolving one PBS tablet in $200 \mathrm{~mL}$ of deionised water at $25^{\circ} \mathrm{C}$, yielding a concentration of $0.01 \mathrm{~mol} / \mathrm{L}$ phosphate buffer, $0.0027 \mathrm{~mol} / \mathrm{L} \mathrm{KCl}$ and $0.137 \mathrm{~mol} / \mathrm{L}$ $\mathrm{NaCl}$ (pH 7.4).

After recording its initial weight, each scaffold was placed in a separate well of a 12-well cell culture plate containing $5 \mathrm{~mL}$ of PBS. Cell plates were placed in an incubator shaker (Innova 43, News Brunswick Scientific, Nijmegen, the Netherlands) operating at $37^{\circ} \mathrm{C}$ and agitation of $60 \mathrm{rpm}$. The buffer solutions were replaced twice a week with fresh PBS. At each predetermined time interval (1, 2 or 3 weeks), scaffolds were removed from the medium, washed with distilled water to remove remaining medium and freeze-dried to ensure a constant weight. Afterwards, scaffolds were weighed again and the degradation rate was calculated using the equation:

$$
\text { Degradation rate }(\%)=\frac{W_{0}-W_{t}}{W_{0}} \times 100
$$

where $W_{0}$ denotes the original sample weight and $W_{t}$ the sample weight at the selected time point.

For each combination of scaffold type and degradation period, one replicate was examined by SEM, as described above, to compare the pore structure after varying degradation periods (1, 2 and 3 weeks) with the original pore structure.

\section{Bioactivity testing}

The scaffolds' bioactivity contributes to their potential to form an apatite layer (i.e. hydroxyapatite). The apatite-forming ability of all types of scaffolds was investigated by immersion in SBF, a medium with ion concentrations nearly equal to those of human blood plasma, following the technique suggested by Kokubo and Takadama (2006).
To obtain a consistent ratio of liquid to scaffold surface area, the required volume of SBF for each sample was calculated using the equation (Kokubo and Takadama, 2006):

$$
V_{s}=S_{a} / 10
$$

where $V_{s}$ is the volume of SBF (in $\mathrm{mL}$ ) and $S_{a}$ is the apparent surface area of the sample (in $\mathrm{mm}^{2}$ ).

For the disk-shaped samples, applying the formula resulted in a SBF volume of $\sim 32 \mathrm{~mL}$. For porous samples, the required volume of SBF should be larger than the calculated $V_{s}$ and, therefore, a volume of $40 \mathrm{~mL} \mathrm{SBF}$ for each sample was chosen. Three replicates of each type of scaffold were immersed in $40 \mathrm{~mL} \mathrm{SBF}$ at $37^{\circ} \mathrm{C}$ up to 3 weeks, with scaffolds being removed after 1 and 3 weeks. From day 7 onwards, the SBF was refreshed twice a week. At each selected time point, samples were removed from the SBF solution, rinsed with distilled water to remove the remaining SBF solution and dried using a vacuum desiccator (Dimida et al., 2017; Kokubo and Takadama, 2006). For each combination of scaffold type and immersion time, two replicates were examined by SEM with associated EDX (EDAX, Tilburg, the Netherlands). Analysis was performed at an accelerating voltage of $15 \mathrm{kV}$, a spot size of 6 and a $11 \mathrm{~mm}$ working distance. Apatite formation can be recognised by a characteristic needle-like layer or by a $\mathrm{Ca} / \mathrm{P}$ ratio around 1.67 (Chen et al., 2015). Further, one replicate was examined by XRD (Bruker, D2 Phaser) to determine if apatite was present or not. Prior to the measurements, the chitosan scaffolds were milled using a mortar and pestle. A coupled $2 \theta / \theta$ scan type (range of $5-80^{\circ}$ in $2 \theta$ ) was used, using $\mathrm{CuK}_{\alpha}(\lambda=0.15405 \mathrm{~nm})$ radiation as the source at a rate of $2^{\circ} / \mathrm{min}$, a voltage of $40 \mathrm{kV}$ and a current of $30 \mathrm{~mA}$. The analysis software HighScore Plus (Malvern Panalytical, Malvern, UK) was used to identify the peaks observed in the obtained XRD spectra.

\section{Biological evaluation \\ Primary cell cultures}

Dental pulp tissues were acquired with informed consent from patients (15-20 years of age, male and female) undergoing extraction of third molars for therapeutic or orthodontic reasons. Written informed consent was obtained from the patients and/or their parents, as approved by the medical ethical committee of Hasselt University, Belgium (protocol 13/0104U). Pulp tissue was obtained using forceps after mechanically fracturing the extracted and disinfected tooth with surgical chisels. Pulp tissue was rinsed and kept at $37^{\circ} \mathrm{C}$ in $\alpha \mathrm{MEM}$ supplemented with $2 \mathrm{mmol} / \mathrm{L}$ L-glutamine, $100 \mathrm{U} / \mathrm{mL}$ penicillin, $100 \mu \mathrm{g} / \mathrm{mL}$ streptomycin and $10 \%$ FBS. hDPSCs were isolated according to the explant method and expanded in culture, as described previously (Hilkens et al., 2013). Cells were cultured in $\alpha \mathrm{MEM}$, enriched with $10 \%$ heat-inactivated FBS, $2 \mathrm{mmol} / \mathrm{L}$ L-glutamine, $100 \mathrm{U} / \mathrm{mL}$ penicillin and $100 \mu \mathrm{g} / \mathrm{mL}$ 
streptomycin. Only mycoplasma negative cells, screened using the PlasmoTest ${ }^{\mathrm{TM}}$ kit (InvivoGen), were used. All hDPSC cultures were tested by means of flow cytometry for the expression at the protein level of the following mesenchymal cell markers, as described previously (Hilkens et al., 2013): positive for CD29, CD73, CD90 and CD105; negative for CD31, CD34 and CD45.
Evaluation of hDPSC viability and metabolic activity To obtain sterile scaffolds, $24 \mathrm{~h}$ before seeding, scaffolds were placed in $70 \% \mathrm{EtOH}$ for $2 \mathrm{~h}$, washed with PBS, placed in a 96-well plate and stored in an incubator until the next step. $5 \times 10^{5}$ cells/mL hDPSCs were seeded in $40 \mu \mathrm{L}$ of serum-free MSC medium on top of an uncoated scaffold ( $n=9$, per scaffold composition and time point) or a scaffold coated with

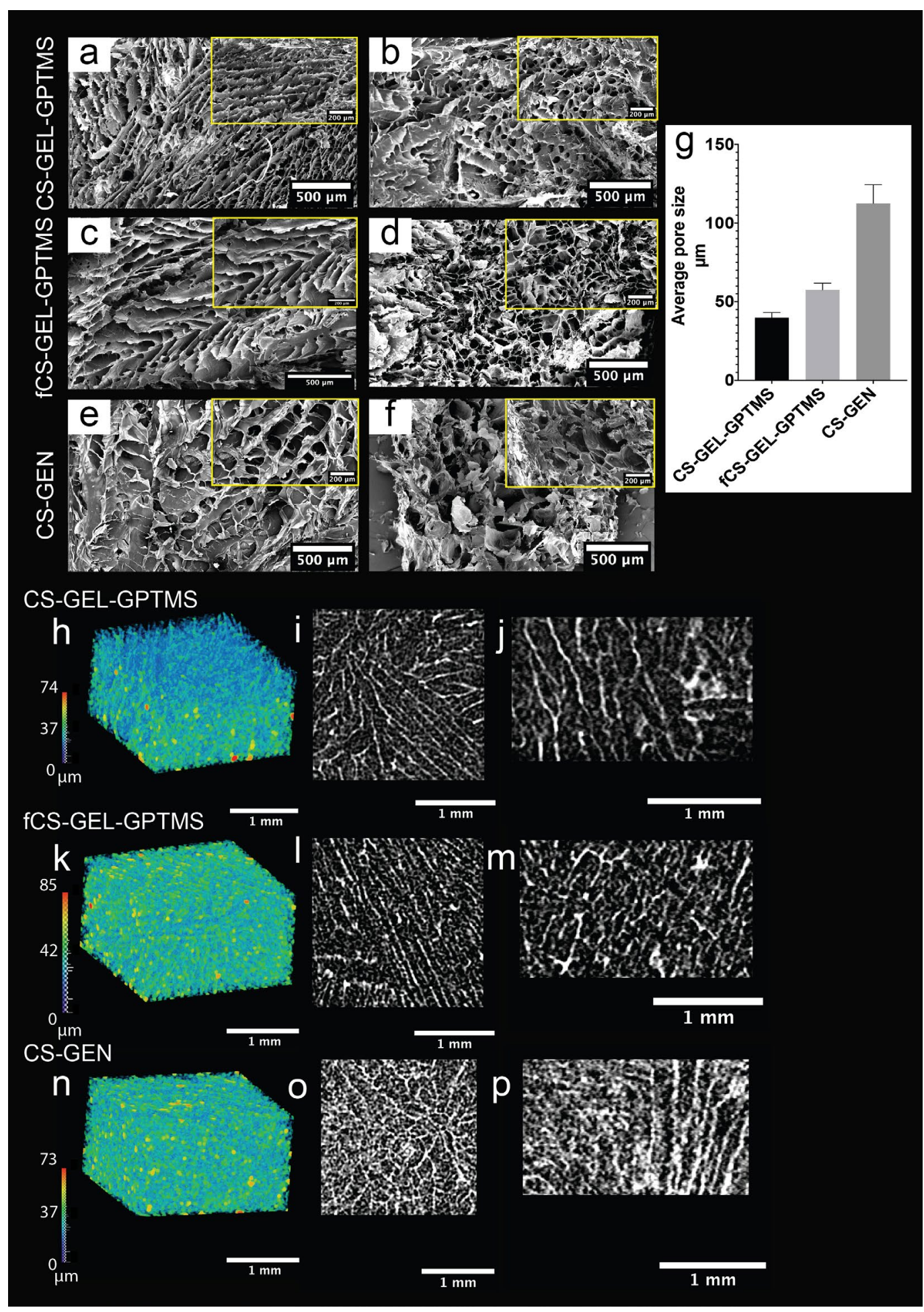

Fig. 2. Scaffolds microstructure. (a-f) Representative SEM images (higher magnification in the top right corner of each image) of $(\mathbf{a}, \mathbf{c}, \mathbf{e})$ transverse cross-sections showing radially oriented pores and $(\mathbf{b}, \mathbf{d}, \mathbf{f})$ longitudinal cross-sections. (g) Average pore size as measured from SEM images. (h-p) Representative nanoCT images. (h,k,n) 3D map of the strut thickness in a $2 \times 2 \times 1 \mathrm{~mm}$ ROI from the different scaffolds. (i,l,o) Transverse cross-sections and $(\mathbf{j}, \mathbf{m}, \mathbf{p})$ longitudinal cross-sections, both showing radially oriented pores. 
$20 \mu \mathrm{g} / \mathrm{mL}$ fibronectin ( $n=9$, per scaffold composition and time point). In addition, scaffolds devoid of cells were prepared and served as blank replicates to remove background signal. Cells were allowed to attach for $30 \mathrm{~min}$, then $200 \mu \mathrm{L}$ of serum-free MSC medium supplemented with $2 \mathrm{mmol} / \mathrm{L}$ L-glutamine, $100 \mathrm{U} / \mathrm{mL}$ penicillin and $100 \mathrm{\mu g} / \mathrm{mL}$ streptomycin was added to each well. $2 \mathrm{D}$ controls of $5 \times 10^{3}$ cells were seeded in a 96-well plate in two different types of culture medium: $\alpha \mathrm{MEM}$ supplemented with $2 \mathrm{mmol} / \mathrm{L}$ L-glutamine, $100 \mathrm{U} / \mathrm{mL}$ penicillin, $100 \mu \mathrm{g} /$ $\mathrm{mL}$ streptomycin and $10 \%$ FBS or serum-free MSC medium (same composition as the medium used for the scaffolds). After 1, 2,3 and $7 \mathrm{~d}$ in culture, scaffolds were transferred to a new well and an alamarBlue solution (1/10 volume of the culture medium) was added to each well and incubated for $2 \mathrm{~h}$ at $37^{\circ} \mathrm{C}$ and $5 \% \mathrm{CO}_{2}$. After incubation, the medium was transferred to a 96-well plate and the fluorescence excitation/emission was measured at 560/590 nm using a microplate reader (Varioskan ${ }^{\mathrm{TM}}$, Thermo Fisher Scientific). Readings of the blank replicates were subtracted to obtain the actual cell signal.

\section{Statistical analysis}

Statistical analysis was performed using GraphPad Prism for MacOS, version 9.0. (GraphPad Software). Statistical analysis (IQR method) was carried out to determine outliers and exclude them from the compressive modulus calculation. The influence of the different scaffold compositions on the compressive modulus was tested using a one-way ANOVA. The influence of the different experimental conditions and the time factor on scaffold degradation rate and cell viability was modelled using a two-way ANOVA. All ANOVA tests were followed by Tukey's correction for multiple comparisons. Statistical significance was determined at $p<0.05$. Descriptive statistics are represented as mean \pm standard deviation.

\section{Results}

\section{Microstructure of fabricated chitosan scaffolds}

The fabrication method used was successful in producing porous scaffolds. Fig. 2 shows representative SEM cross-sectional images of the chitosan scaffolds fabricated either in the transversal (Fig. 2a,c,e) or in the longitudinal direction (Fig. $2 \mathbf{b}, \mathbf{d}, \mathbf{f})$. It can be observed that all scaffolds exhibited a significantly different pore structure in the transverse cross-section as compared to the longitudinal crosssection. This pore anisotropy was obtained by manipulating the cooling direction during solution moulding by using dry ice only on the sides of the mould. The transverse cross-section consisted of elongated pores or radially oriented lines of pores (Fig. 2a,c,e), while these radially oriented pores were not well observed in the longitudinal crosssection. The average pore diameter of the scaffolds was determined by analysis of SEM images of the transverse cross-sections (Fig. 2g). CS-GEN scaffolds showed the largest pore diameter of $112.6 \pm 11.8 \mu \mathrm{m}$, followed by fCS-GEL-GPTMS scaffolds, with a pore diameter of $57.4 \pm 4.3 \mu \mathrm{m}$. CS-GEL-GPTMS scaffolds had the smallest pore diameter of $39.8 \pm 3.2 \mu \mathrm{m}$.

Nano-CT was used as an additional technique to evaluate the $3 \mathrm{D}$ pore structure of the fabricated scaffolds. Fig. 2h-p shows a 3D map of the scaffold strut thickness together with a representative transverse and longitudinal cross-section for the selected scaffolds. The radially oriented pores were observed in the transverse cross-sections of all investigated scaffolds, which matched the observations in the SEM images. Additionally, this desired pore directionality was also observed in the longitudinal cross-sections. Scaffold porosity and mean strut thickness, as calculated from the nano-CT data, revealed a comparable porosity level and mean strut thickness between all three scaffold compositions. This was $38.7 \%$ porosity for CS-GEL-GPTMS, with a mean strut thickness of $27.1 \pm 12.2 \mu \mathrm{m} ; 36.6 \%$ porosity for CS-GEN, with a mean strut thickness of $26.4 \pm 11.3 \mu \mathrm{m} ; 34.2 \%$ porosity for fCS-GEL-GPTMS, with a mean strut thickness of $27.2 \pm 11.6 \mu \mathrm{m}$

Finally, the nano-CT datasets were used to calculate the FD of the scaffolds struts as a measure of 3D surface roughness. All scaffold compositions had a FD value close to 3, indicating a high surface roughness. This was $2.8 \pm 0.006$ for CS-GEL-GPTMS scaffolds, $2.8 \pm 0.003$ for fCS-GEL-GPTMS scaffolds and $2.7 \pm 0.001$ for CS-GEN scaffolds.

\section{Chemical composition and cross-linking}

All tested sample spectra showed absorption bands at 2,800-3,000 $\mathrm{cm}^{-1}$ and a broad band between 3,000-3,600 $\mathrm{cm}^{-1}$, which could be attributed to C-H stretching vibrations (symmetric and asymmetric) and an overlap of amine and alcohol stretching vibrations, respectively (Chiono et al., 2008; Klein et al., 2016). For the sake of simplicity, these bands are not shown and only the wave number range from 1,800 to $650 \mathrm{~cm}^{-1}$ is presented.

The FTIR spectra for scaffolds obtained from animal chitosan (CS-GEL-GPTMS, Fig. 3a) and fungal chitosan (fCS-GEL-GPTMS, Fig. 3b) were similar, with approximately the same peaks, although some smaller differences could be observed. The cross-linking of GPTMS with chitosan consisted of the reaction between amine groups of the chitosan with oxirane groups in the GPTMS. This could be observed by an intensity decrease in the absorption band at $1,552 \mathrm{~cm}^{-1}$, attributed to the $\mathrm{N}-\mathrm{H}$ bending of the primary amine (Liu et al., 2004). The N-H bending peak was more intense in the fCS-GEL-GPTMS spectrum, suggesting a lower degree of cross-linking (Liu et al., 2004). All spectra showed bands around $1,021 \mathrm{~cm}^{-1}$ and $920 \mathrm{~cm}^{-1}$, which could be assigned to the Si-O-Si and $\mathrm{Si}-\mathrm{OH}$ stretching, respectively (Connell et al., 2014; Liu et al., 2004; Tonda-Turo et al., 2011). The presence of these bands was characteristic 
for the cross-linking mechanism of GPTMS. In these spectra, bands at $1,020 \mathrm{~cm}^{-1}$ and $910 \mathrm{~cm}^{-1}$ were observed, associated with $\mathrm{Si}-\mathrm{O}-\mathrm{Si}$ bonds and $\mathrm{Si}-\mathrm{OH}$ stretching, respectively. The presence of these bonds confirmed the successful cross-linking between chitosan and gelatine by GPTMS (Tonda-Turo et al., 2011).

Fig. 3c shows the spectra for scaffolds obtained from animal chitosan crosslinked to genipin
(CS-GEN), confirming successful cross-linking as demonstrated by the presence of new peaks indicating the reaction between chitosan and genipin and the disappearance of peaks characteristic of the starting materials. The cross-linking of genipin with chitosan is a two-step process. The first, and fastest, reaction consists of the nucleophilic attack by the amino group of chitosan on the olefinic carbon atom at $\mathrm{C} 3$ of genipin, resulting in an opening of the
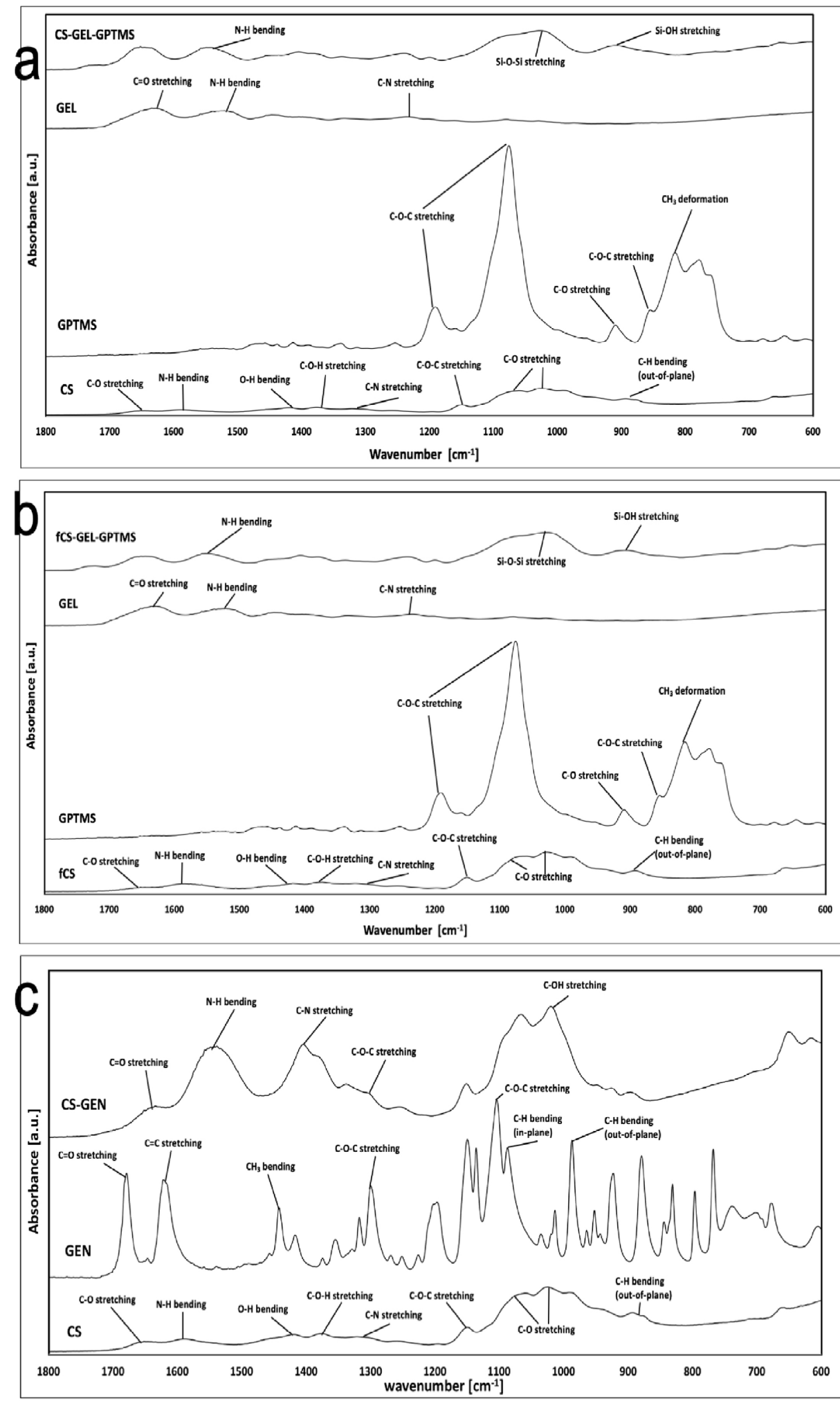

Fig. 3. Chemical composition and cross-linking. FTIR spectra of the chitosan scaffolds tested in comparison to the respective starting materials. (a) CS-GEL-GPTMS, (b) fCS-GEL-GPTMS, (c) CS-GEN. 
dihydropyran ring and formation of a tertiary amine (i.e. a heterocyclic compound of genipin cross-linked to polymers containing primary amine groups) (Cui et al., 2014; Klein et al., 2016). In the FTIR spectra, this reaction can be seen by an increase in the intensity of the C-N band around $1,078 \mathrm{~cm}^{-1}$ (Cui et al., 2014). The subsequent slower reaction is a nucleophilic substitution that forms an amide through the reaction of the amino group on chitosan with the ester carboxymethyl group (by C11) of genipin (Cui et al., 2014; Klein et al., 2016). This can be observed by the secondary amide band at $1,546 \mathrm{~cm}^{-1}$ (characteristic of
$\mathrm{N}-\mathrm{H}$ bending) and the peak at $1,633 \mathrm{~cm}^{-1}$, assigned to $\mathrm{C}=\mathrm{O}$ stretching in secondary amides (Klein et al., 2016). Additionally, the increase in the peaks around $1,404 \mathrm{~cm}^{-1}$ and $1,015 \mathrm{~cm}^{-1}$ could be attributed to $\mathrm{C}-\mathrm{N}$ stretching and $\mathrm{C}-\mathrm{OH}$ stretching vibrations, respectively (Klein et al., 2016).

Animal chitosan gelatine co-polymerisation increases scaffold compressive strength

CS-GEL-GPTMS scaffolds showed the highest compressive modulus ( $364 \pm 30 \mathrm{kPa})$. This was 3-fold higher than scaffolds fabricated with the fungal
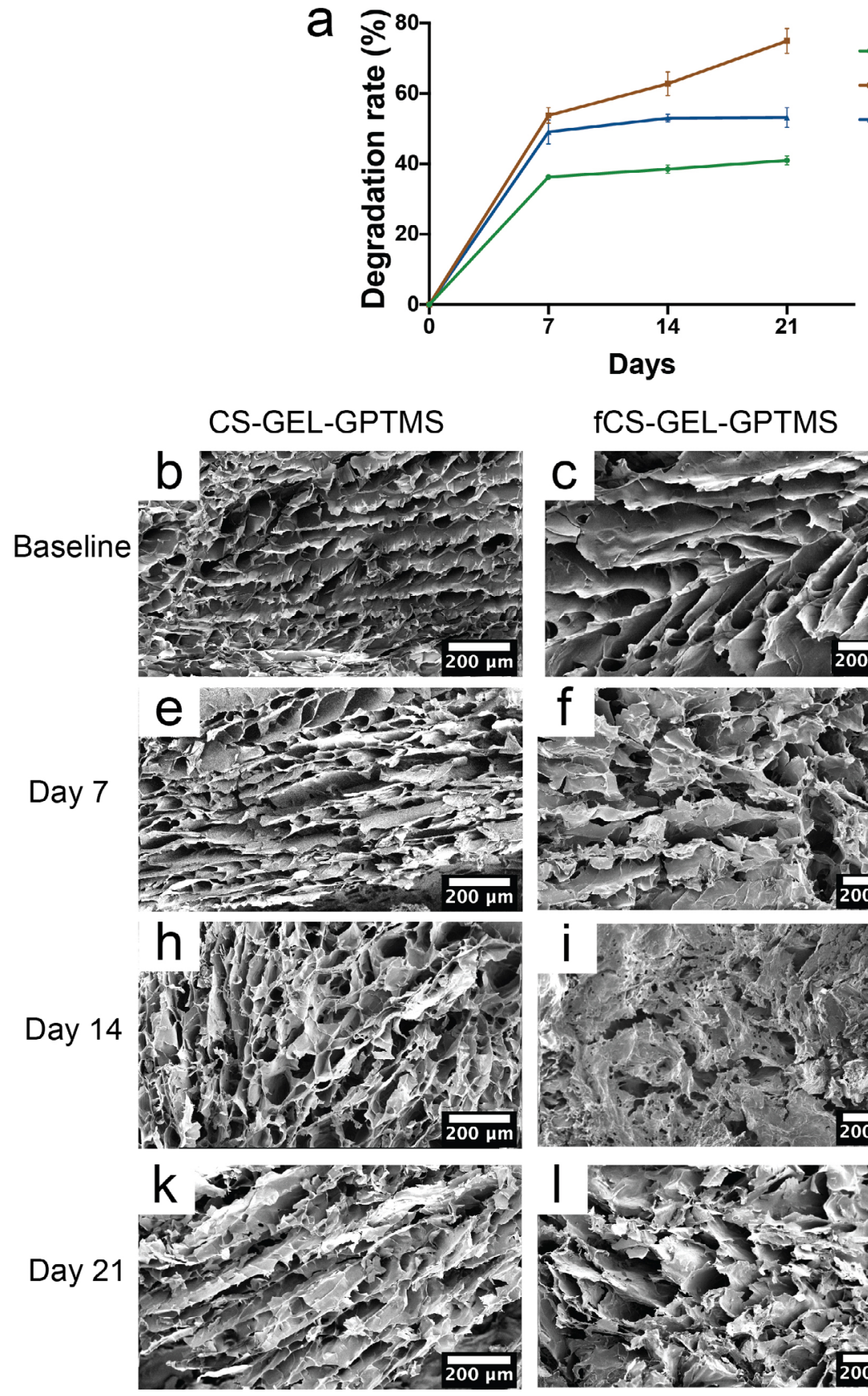

\section{fCS-GEL-GPTMS}
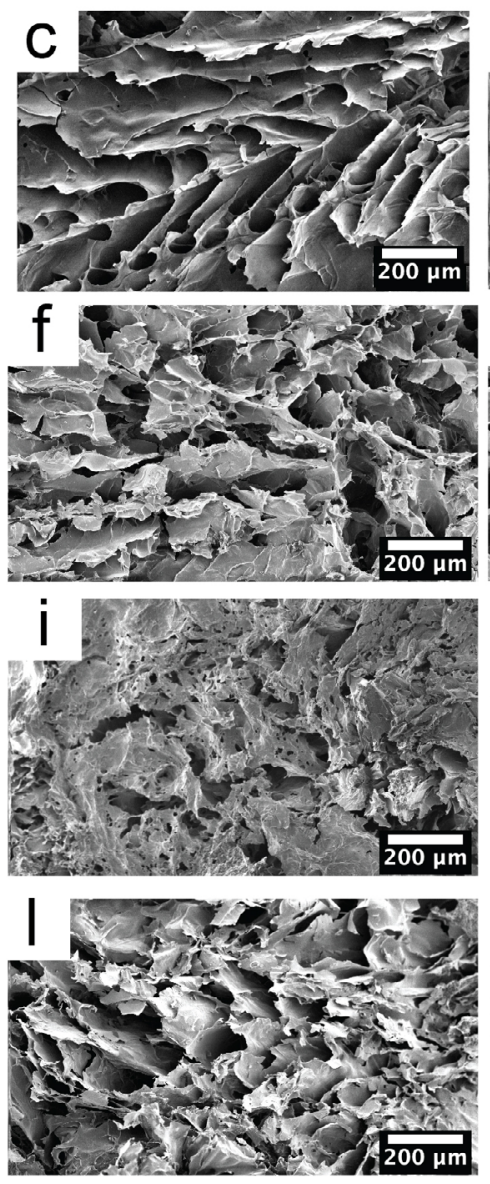

- CS-GEL-GPTMS

- fCS-GEL-GPTMS

- CS-GEN

Fig. 4. Scaffolds degradation. (a) Hydrolytic degradation rate of the chitosan scaffolds showing fastest degradation rate for fCS-GEL-GPTMS scaffolds, reaching $80 \%$ by $21 \mathrm{~d}$. Data are represented as mean \pm standard deviation. (b-m) Representative SEM images of scaffold degradation up to $21 \mathrm{~d} ;(\mathbf{f}, \mathbf{g})$ fCS-GELGPTMS and CS-GEN scaffolds showing wider pores and rougher surfaces at $7 \mathrm{~d} ;(\mathbf{i}, \mathbf{l})$ fCS-GEL-GPTMS scaffolds showing progressive degradation leading to loss of structural organisation at 14 and $21 \mathrm{~d}$ matching the gravimetric results in a. 
chitosan (fCS-GEL-GPTMS) (122 $\pm 9 \mathrm{kPa})$ and 5-fold higher than scaffolds fabricated only with animal chitosan without gelatine and crosslinked using genipin $(67 \pm 15 \mathrm{kPa})$.

\section{Scaffold degradation affected by chitosan source and type of cross-linker}

Scaffolds with fungal chitosan (fCS-GEL-GPTMS) showed the fastest degradation rate in PBS, followed by CS-GEN and CS-GEL-GPTMS scaffolds, respectively (Fig. 4a). There was a significant $(p<0.05)$ effect on scaffold degradation rate based on scaffold composition $[\mathrm{F}(2,6)=363.1, p<0.0001]$ and time point $[\mathrm{F}(1.63,9.79)=1244, p<0.0001]$. Post-hoc comparisons by Tukey test showed that fCS-GEL-GPTMS scaffolds were degrading faster when compared to CS-GELGPTMS scaffolds at all time points $(p<0.05)$, while the difference in degradation rate was only statistically significant at day 21 compared to CS-GEN scaffolds $(p<0.05)$. The differences between CS-GEL-GPTMS and CS-GEN scaffolds were statistically significant at all time points $(p<0.05)$. For the two groups with animal chitosan, the greatest bulk of degradation occurred in the first $7 \mathrm{~d}$, afterwards the degradation rate seemed to plateau up to day 21 . This was in contrast with the observations for the fungal chitosan group, where the degradation progressed steadily up to day 21 (Fig. 4a). The results from the gravimetric analysis were confirmed by the SEM images for the scaffolds at the different experimental time points (Fig. 4b-m). fCS-GEL-GPTMS scaffolds showed an increase in pore size, pore irregularity and pore surface roughness, with the porous structure changed in a sheet-like structure with bigger pores after degradation (Fig. 4c,f,i,l).

Gelatine as a co-polymer enhanced chitosan scaffolds bioactivity through the formation of an apatite layer

After $7 \mathrm{~d}$ of soaking in SBF solution, no CaP deposits could be detected on any of the scaffolds (results not shown). All spectra showed high peaks of carbon, which could be explained by chitosan (since it mainly consists of $\mathrm{C}, \mathrm{O}$ and $\mathrm{H}$ ) and the use of a carbon coating. Furthermore, traces of $\mathrm{Ca}, \mathrm{P}, \mathrm{S}, \mathrm{K}, \mathrm{Mg}$ were detected on the surface of all scaffolds, which could also be explained by the immersion in SBF.

After $21 \mathrm{~d}$ in SBF, CaP deposits could be observed on chitosan/gelatine blend scaffolds (CS-GEL-GPTMS and fCS-GEL-GPTMS) (Fig. 5a-d). The EDX spectra
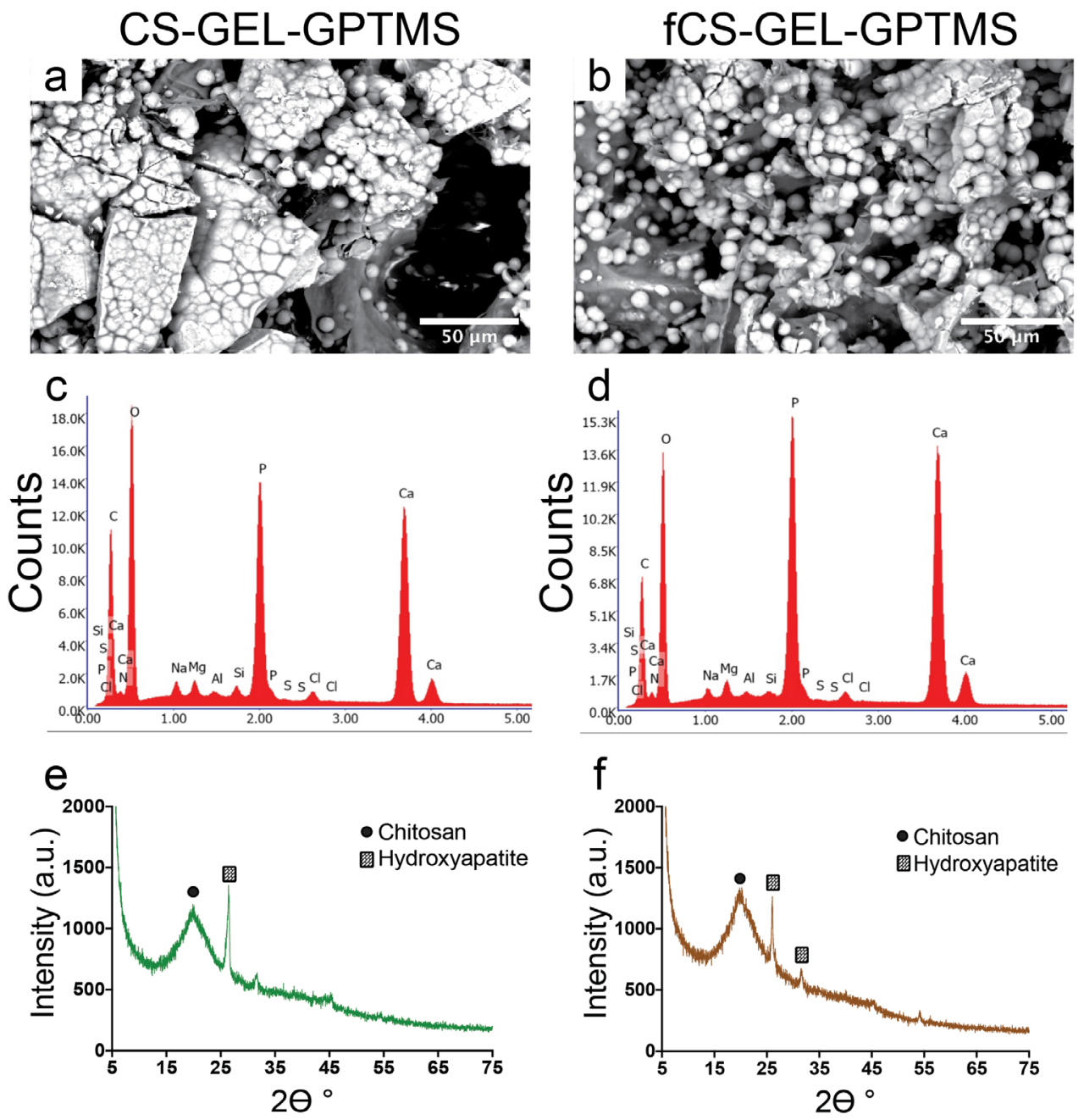

Fig. 5. Scaffold bioactivity. (a,b) Representative SEM images and (c,d) corresponding EDX point analysis after $21 \mathrm{~d}$ in SBF, showing high levels of $\mathrm{Ca}$ and $\mathrm{P}$ deposition characteristic of hydroxyapatite formation. $(\mathbf{e}, \mathbf{f})$ XRD analysis confirming the formation of hydroxyapatite crystals. 

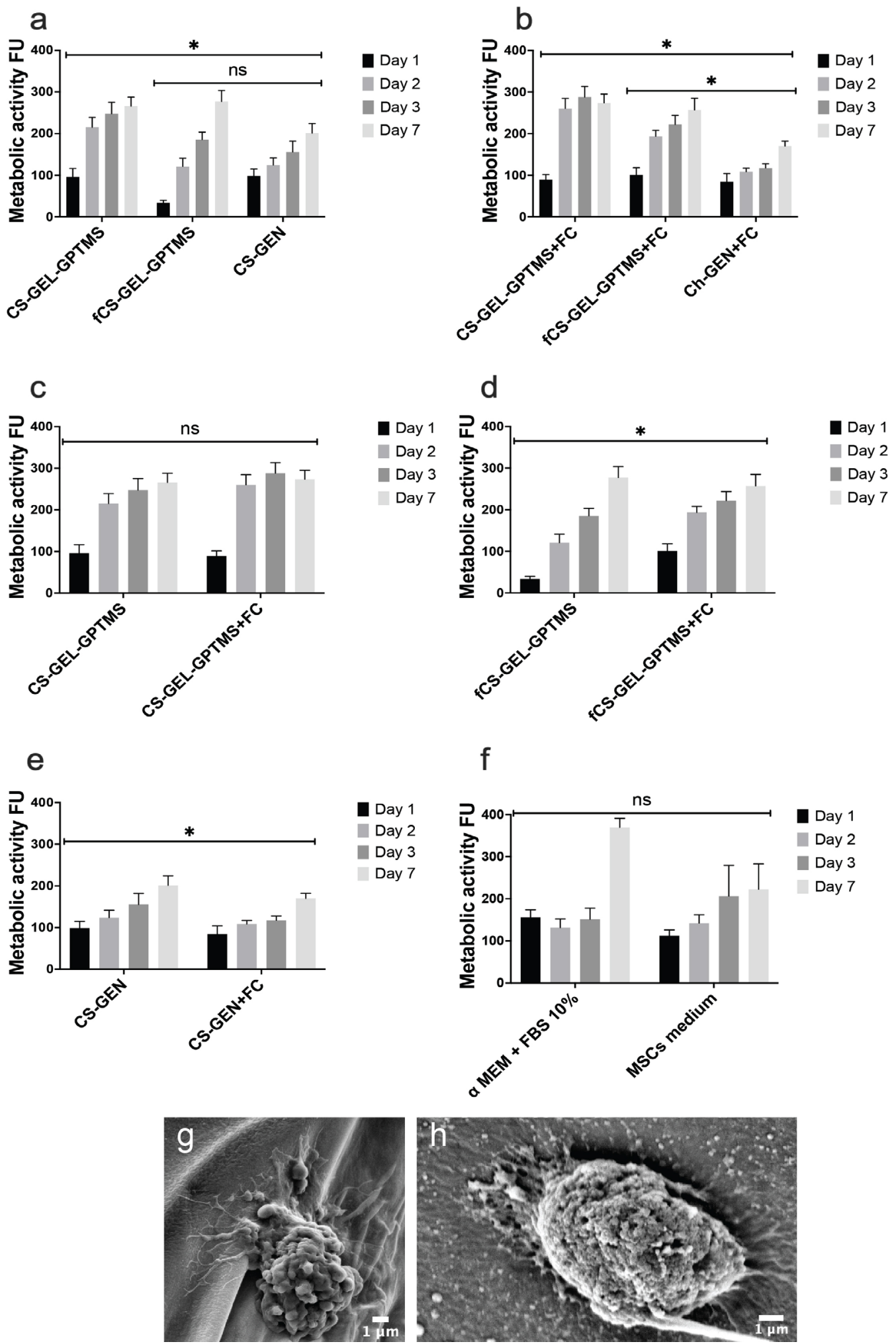

Fig. 6. hDPSCs metabolic activity. (a) hDPSCs metabolic activity up to $7 \mathrm{~d}$ in response to scaffolds showing a favourable cellular response to all chitosan scaffolds, with significantly higher viability in response to CSGEL-GPTMS scaffolds over the experimental period. (b) Metabolic activity in response to scaffolds coated with fibronectin (FC). ANOVA showing significantly higher viability in response to CS-GEL-GPTMS with FC scaffolds compared to the other two groups and significantly higher viability for fCS-GEL-GPTMS with FC scaffolds compared to the Ch-GEN with FC scaffolds. (c) Cellular response to CS-GEL-GPTMS scaffolds was not affected by the addition of FC, while (d) a positive effect was observed with fCS-GELGPTMS and (e) a negative effect with CS-GEN scaffolds. (f) 2D controls in different cell culture media. (g,h) Representative SEM images for hDPSCs attached to the scaffold surface (g) CS-GEL-GPTMS and (h) fCS-GEL-GPTMS. Data are represented as mean \pm standard deviation. ${ }^{*}$ statistically significant; ns: not significant. FU: fluorescence unit. 
Table 1. Detected Ca (wt. \%), P (wt. \%) and Ca/P ratio of 5-point analysis on the animal- and fungalderived chitosan/gelatine blend scaffolds (CS-GEL-GPTMS and fCS-GEL-GPTMS). Data are represented as mean \pm standard deviation.

\begin{tabular}{|c|c|c|c|}
\hline Sample code & Ca $($ wt. $\%)$ & $\mathbf{P}($ wt. $\%)$ & Ca/P ratio \\
\hline CS-GEL-GPTMS & $22.33( \pm 9.55)$ & $11.73( \pm 5.55)$ & $1.98( \pm 0.22)$ \\
\hline fCS-GEL-GPTMS & $26.27( \pm 3.62)$ & $13.86( \pm 1.65)$ & $1.89( \pm 0.07)$ \\
\hline
\end{tabular}

showed the presence of Si related to the use of GPTMS and $C$ related to chitosan. Additionally, traces of SBF $(\mathrm{Ca}, \mathrm{P}, \mathrm{S}, \mathrm{K}, \mathrm{Mg})$ and some $\mathrm{NaCl}$ crystals were detected at distinct positions on the surface of the scaffolds. However, the chitosan/gelatine blend scaffolds (CSGEL-GPTMS and fCS-GEL-GPTMS) showed some clear $\mathrm{Ca}$ and $\mathrm{P}$ peaks (Fig. 5c,d). Moreover, the $\mathrm{CaP}$ deposits showed a typical cauliflower structure of hydroxyapatite crystals on the SEM images (Fig. $5 \mathbf{a}, \mathbf{b})$. XRD analysis at $21 \mathrm{~d}$ suggested the formation of HA crystals on the surface of chitosan/gelatine blend scaffolds (CS-GEL-GPTMS and fCS-GEL-GPTMS) (Fig. 5e,f). To further investigate the deposits on CS-GEL-GPTMS and fCS-GEL-GPTMS scaffolds, the average $\mathrm{Ca} / \mathrm{P}$ ratio was calculated by examining 5 different points at the surface by EDX (Table 1). $\mathrm{A} \mathrm{Ca} / \mathrm{P}$ ratio of 1.98 and 1.89 was found for animal chitosan/gelatine blend scaffolds (CS-GEL-GPTMS) and fungal chitosan/gelatine blend scaffolds (fCSGEL-GPTMS), respectively. It should be noted that small amounts of $\mathrm{Ca}$ and $\mathrm{P}$ were also detected on the CS-GEN scaffolds at very high magnification (results not shown). However, since this was only observed at a very small area on the scaffold surface, the $\mathrm{Ca} / \mathrm{P}$ ratio was not further analysed.

\section{Fabricated scaffolds supported hDPSCs attachment} and viability

Overall, the 3 scaffold compositions tested all showed the ability to support hDPSCs attachment and viability as demonstrated by the increased metabolic activity over the experimental period, as assessed by alamarBlue assay (Fig. 6a-b). There was a significant $(p<0.05)$ effect on hDPSC metabolic activity based on scaffold composition $[\mathrm{F}(2,128)=32.81, p<0.0001]$ and time point $[\mathrm{F}(3,128)=30.76, p<0.0001]$. Post-hoc comparisons by Tukey test showed a significantly higher metabolic activity in response to CS-GELGPTMS scaffolds when compared to the other 2 groups $(p<0.05)$, suggesting a better cell attachment and proliferation pattern (Fig. 6a). The addition of fibronectin did not affect cell behaviour in response to CS-GEL-GPTMS scaffolds $(p>0.05)$ (Fig. 6c). This was in contrast with the results obtained for fCS-GEL-GPTMS scaffolds, where a significant positive effect could be observed after the addition of fibronectin $(p<0.05)$ (Fig. 6d). Surprisingly, the addition of fibronectin had a slightly negative effect when added to the CS-GEN scaffolds as compared to scaffolds without fibronectin (Fig. 6e). There were no differences in cell metabolic activity in cells cultured as $2 \mathrm{D}$ controls in different culture media $(p>0.05)$
(Fig. 6f), supporting the use of serum-free MSC medium in hDPSCs cultures.

\section{Discussion}

Dental conditions such as caries, trauma and developmental anomalies frequently affect the developing permanent teeth, leading to tissue or even whole tooth loss (Kassebaum et al., 2014; Kassebaum et al., 2017; Petti et al., 2018). The roots of immature teeth with pulp necrosis fail to develop and are left functionally compromised on the longterm due to arrested dentine formation (Murray et al., 2007). Dental tissue engineering has emerged as a valuable solution for dentine-pulp complex repair/ regeneration and eventually tooth replacement through the fabrication of bioengineered tooth-root. Scaffolds are key elements in the development of any tissue engineering solution, as they provide a temporary 3D structures to support cellular attachment, migration, proliferation and guided differentiation (Ceccarelli et al., 2017; Galler and D'Souza, 2011; Galler et al., 2010). In general, scaffolds should possess the following characteristics: biocompatibility; inter-connected porosity; patientspecificity, with mechanical properties allowing surgical handling; biodegradability; and should mimic the ECM and promote appropriate cell behaviours (Albuquerque et al., 2014; Huang and Garcia-Godoy, 2014; Larsson et al., 2016). Chitosan is a natural biopolymer that possess several of the required scaffolds characteristics, as summarised in the introduction, in addition to antimicrobial properties and induction of M2 macrophage polarisation through elected immune-reaction profile (Caires et al., 2018; 2016).

The present study focused on the fabrication and characterisation of customised scaffolds made of chitosan from different sources and cross-linkers for dental root tissue engineering. Chitosan scaffolds were prepared by means of emulsion freeze-drying using 3D-printed moulds. While moulds of basic geometries were applied, it can easily be appreciated how patient/tooth specific moulds and subsequently also scaffolds can be fabricated based on low-dose cone beam CT imaging (EzEldeen et al., 2017) and inserted, for example, in the wide canals of immature teeth or bony defects for the delivery of bioactive molecules or stem cells.

Interconnected pores and appropriate pore diameter are required to promote cell seeding and 
diffusion of cells, nutrients, oxygen, waste and growth factors (Hutmacher, 2001; Karageorgiou and Kaplan, 2005). The exact required porosity and pore diameter are dependent on the specific cell type, but it is hypothesised that the average pore diameter should be at least three times the cell size to ensure cell communication (Kim et al., 2017). hDPSCs, which are targeted in dental tissue engineering, are about $10-15 \mu \mathrm{m}$ in size, hence a minimal pore diameter of $\sim 45 \mu \mathrm{m}$ is required. The porosity of the chitosan scaffolds fabricated in the present study ranged between 40 and $112 \mu \mathrm{m}$, depending on the chitosan source and the addition of gelatine as a co-polymer (Fig. 2a-g), which should be sufficient for hDPSC attachment and proliferation. Moreover, as a result of the directional freezing applied during emulsion freeze-drying, pores were radially oriented, as shown by the structural characterisation using SEM and nano-CT (Fig. 2). This directionality mimicked the architecture of natural dentine (Bertassoni, 2017) and might be favourable for hDPSC attachment, proliferation, guided differentiation into odontoblasts and subsequent dentine deposition. Therefore, future studies should focus on determining the effect of different pore diameters and 3D architecture on dental stem cells behaviour.

To improve the stability of the chitosan scaffolds, gelatine was added as a co-polymer and different cross-linking agents were applied (GPTMS or genipin). FTIR analysis proved the successful crosslinking of chitosan and chitosan-gelatine by both GPTMS and genipin (Fig. 3a-c). Moreover, animal and fungal chitosan showed similar chemical composition and cross-linking behaviour. This successful co-polymerisation with gelatine increased the compressive strength of the scaffolds (CS-GELGPTMS and fCS-GEL-GPTMS) compared to CSGEN, suggesting improved handling properties. In addition, chitosan source influenced the compressive strength since scaffolds from animal chitosan had a compression modulus 3-fold higher than fungal chitosan. Very limited information can be found in the literature on the application of fungal chitosan in tissue engineering. However, Nwe et al. (2009) reported a 1.5-fold higher tensile strength for scaffolds from fungal chitosan (Gongronella butleri) $(\mathrm{MW}=50 \mathrm{kDa})$ when compared to scaffolds from animal chitosan. The fungal chitosan used in the present study was obtained from Aspergillus niger $(\mathrm{MW}<30 \mathrm{kDa})$, suggesting that fungal species and MW would influence the properties of fungal chitosan scaffolds.

Another significant effect of the chitosan source was the degradation rate. Scaffolds from fungal chitosan (fCS-GEL-GPTMS) lost $80 \%$ of their weight by $21 \mathrm{~d}$ when compared to $40 \%$ for scaffolds from animal chitosan (CS-GEL-GPTMS) (Fig. 4a). This could be due to a lower MW and DA. This faster degradation rate for fungal chitosan was also reported by Nwe et al. (2009) to be $11 \%$ at $14 \mathrm{~d}$, compared to $2-5 \%$ for scaffolds from animal sources. It can be hypothesised that this faster degradation rate would be beneficial for endodontic applications, where the scaffold is protected by the root canal walls and is expected to degrade at a slower rate. Furthermore, the type of crosslinker seems to influence the degradation rate, suggesting that the use of genipin (CS-GEN) led to a faster degradation compared to GPTMS (CS-GEL-GPTMS), possibly related to its larger pore diameter or the natural origin of genipin.

The formation of calcium phosphates, especially hydroxyapatite $\left[\left(\mathrm{Ca}_{10}\left(\mathrm{PO}_{4}\right)_{6}(\mathrm{OH})_{2}\right]\right.$, having a similar chemical composition to that of the mineral phase of bone and dentine, is important for mimicking the mineralised tissue of natural dentine or alveolar bone (Lluch et al., 2009; Manjubala et al., 2006). The capability of the chitosan scaffolds to stimulate the formation of an apatite layer in vitro was tested by immersing the scaffolds in SBF for 7 and $21 \mathrm{~d}$. The results of the EDX analysis showed clear Ca and $\mathrm{P}$ peaks that were confirmed by XRD to be hydroxyapatite crystals for CS-GEL-GPTMS and fCS-GEL-GPTMS scaffolds (Fig. 5a-f). Moreover, $\mathrm{Ca} / \mathrm{P}$ ratios of 1.98 and 1.89 were found for CS-GELGPTMS and fCS-GEL-GPTMS scaffolds, respectively (Table 1 ). Those values are close to the $\mathrm{Ca} / \mathrm{P}$ ratio of mineral phase of human, which is 1.67 . This is an important parameter, as it has been hypothesised that it is easier for DPSCs to attach and proliferate on a substrate with a ratio close to the one of natural ECM (Liao and Ho, 2010). Other studies have shown that a ratio of approximately 1.85 is characteristic of nonstoichiometric hydroxyapatite phase (Chatzistavrou et al., 2015). Overall, the bioactivity testing results indicated that the combination of gelatine as a copolymer and cross-linking using GPTMS could have a positive effect on the formation of an apatite layer on the surface of the chitosan scaffolds. Therefore, these chitosan scaffolds (CS-GEL-GPTMS and fCSGEL-GPTMS) are suitable for the regeneration of mineralised tissues such as dentine or alveolar bone.

Several authors have successfully reported on the application of different hydrogels in dental pulp tissue engineering (Dissanayaka et al., 2015; Galler et al., 2018; Hilkens et al., 2017; Nakashima et al., 2017). From those hydrogels, fibrin seems to be an excellent candidate for pulp tissue engineering (Galler et al., 2018). Moreover, it has been demonstrated that chitosan incorporation in fibrin hydrogels could enhance the antibacterial properties and immunomodulation in a dental pulp regeneration context (Ducret et al., 2019; Renard et al., 2020). Therefore, gaining a deeper understanding on the effect of chitosan from different sources and the use of different cross-linkers on scaffold properties could aid in the optimisation of such hydrogel systems.

hDPSCs, SCAPs or SHED are mesenchymal stem/ stromal cells that pose the potential to differentiate into numerous cell types in vitro including, odontoblasts, osteoblasts, chondroblasts, adipocytes and neuronal cells (Bronckaers et al., 2013; Bronckaers et al., 2014; Ratajczak et al., 2016). The relative ease of 
accessibility from teeth (e.g. from extracted wisdom molars or exfoliated primary teeth) (Hilkens et al., 2016) renders them a valuable tool for studying and exploring tissue regeneration possibilities in the dentoalveolar and craniofacial regions. hDPSCs were used in the present study to evaluate the scaffolds' biocompatibility. hDPSCs were seeded and cultured in serum-free MSC medium to avoid false positive cell attachment results due to the presence of FBS in commonly used cell culture mediums for hDPSCs. Results demonstrated the suitability of serum-free MSC medium for maintenance and proliferation of hDPSCs (Fig. 6f). This is an important parameter for future translational clinical research to avoid the use of animal components in human cell cultures. The cell metabolic activity delivers indirect information on viability and attachment to porous scaffolds surface (Zhou et al., 2013). All scaffold compositions supported cell viability and attachment up to $7 \mathrm{~d}$ (Fig. 6a,b), however CS-GEL-GPTMS group had the best performance, followed by fCS-GEL-GPTMS (Fig. 6a). This could be explained by the presence of the integrin-binding RGD-like sequence in gelatine, which will promote cellular attachment (Kumar et al., 2017). Moreover, it has been reported that the Si$\mathrm{OH}$ and $\mathrm{Si}-\mathrm{O}-\mathrm{Si}$ groups, derived from GPTMS, can promote MG-63 osteoblast-like cells attachment and proliferation, indicating the importance of silicate ions in the promotion of cell differentiation (TondaTuro et al., 2011). These Si-OH and Si-O-Si groups were also observed in the FTIR data from the current study, which may offer an additional explanation for the hDPSC favourable response to CS-GELGPTMS and fCS-GEL-GPTMS groups. Moreover, hDPSC attachment and proliferation seemed to be inversely proportional to the pore diameter as CS-GEN scaffolds had the largest pore diameter, followed by fCS-GEL-GPTMS and CS-GEL-GPTMS (Fig. $2 \mathrm{~g}$ and $6 \mathbf{a}, \mathbf{b}$ ). Future studies should apply deep learning algorithms (in silico modelling) on combined structural and biological data to identify the main variables influencing specific cellular responses for optimised scaffold design and fabrication (Geris et al., 2018).

\section{Conclusion}

The present study presented data on a practical fabrication method of scaffolds with organised porosity, utilising CAD and 3D printing, which have become a common clinical practice in the last decade. The use of fungal-derived chitosan was explored for its desirable properties of reduced risk of allergic reaction, low molecular weight and enhanced antimicrobial properties. This was followed by a comprehensive characterisation showing the effect of chitosan source, co-polymerisation with gelatine and different cross-linkers on the structural and biological properties of the scaffolds. The proposed scaffolds combined with bioactive molecules could have a direct clinical application in cell-free regenerative endodontics of immature teeth to control infections, induce dentine formation and root development. Moreover, tailored scaffolds could be modified through the addition of inorganic components such as tricalcium phosphate or bioactive glass for alveolar bone regeneration. Further work will focus on obtaining a deeper understanding of stem-cell and immune-cell behaviour in response to the scaffolds to optimise their application in dento-alveolar tissue engineering.

\section{Acknowledgements}

The study was supported by the Research Council of KU Leuven, grant number C24/18/068. AB acknowledges the receipt of a starting grant from Internal Funds KU Leuven (STG/17/024). The authors would like to thank Prof. Koen Binnemans (KU Leuven, Department of Chemistry) for the use of the FTIR device. Also thanks to Prof. Ivo Lambrichts (U Hasselt) and Prof. Annelies Bronckaers (U Hasselt) for providing the hDPSCs and the continued collaboration.

$\mathrm{ME}$, JL, AB and RJ contributed to the conception, design, data acquisition, analysis, interpretation as well as drafted and critically revised the manuscript; $\mathrm{ZN}, \mathrm{DM}$ and MC contributed to data acquisition, analysis, interpretation and critically revised the manuscript. All authors gave final approval and agreed to be accountable for all aspects of the study. The authors deny any conflicts of interest.

\section{References}

Albuquerque MT, Valera MC, Nakashima M, Nor JE, Bottino MC (2014) Tissue-engineering-based strategies for regenerative endodontics. J Dent Res 93: 1222-1231.

Amancio MA, Pinto EP, Matos RS, Nobre FX, Brito WR, da Fonseca Filho HD (2020) Nanoscale morphology and fractal analysis of $\mathrm{TiO} 2$ coatings on ITO substrate by electrodeposition. J Microsc. DOI: 10.1111/jmi.12990.

Austah O, Joon R, Fath WM, Chrepa V, Diogenes A, Ezeldeen M, Couve E, Ruparel NB (2018) Comprehensive characterization of 2 immature teeth treated with regenerative endodontic procedures. J Endod 44: 1802-1811.

Batista ACdL, Souza Neto FEd, Paiva WdS (2018) Review of fungal chitosan: past, present and perspectives in Brazil. Polímeros 28: 275-283.

Bertassoni LE (2017) Dentin on the nanoscale: hierarchical organization, mechanical behavior and bioinspired engineering. Dent Mater 33: 637-649.

Bronckaers A, Hilkens P, Fanton Y, Struys T, Gervois P, Politis C, Martens W, Lambrichts I (2013) Angiogenic properties of human dental pulp stem 
cells. PLoS One 8: e71104. DOI: 10.1371/journal. pone.0071104.

Bronckaers A, Hilkens P, Martens W, Gervois P, Ratajczak J, Struys T, Lambrichts I (2014) Mesenchymal stem/stromal cells as a pharmacological and therapeutic approach to accelerate angiogenesis. Pharmacol Ther 143: 181-196.

Caires HR, Barros da Silva P, Barbosa MA, Almeida CR (2018) A co-culture system with three different primary human cell populations reveals that biomaterials and MSC modulate macrophage-driven fibroblast recruitment. J Tissue Eng Regen Med 12: e1433-e1440.

Caires HR, Esteves T, Quelhas P, Barbosa MA, Navarro M, Almeida CR (2016) Macrophage interactions with polylactic acid and chitosan scaffolds lead to improved recruitment of human mesenchymal stem/stromal cells: a comprehensive study with different immune cells. J R Soc Interface 3: 20160570. DOI: 10.1098/rsif.2016.0570.

Ceccarelli G, Presta R, Benedetti L, Cusella De Angelis MG, Lupi SM, Rodriguez YBR (2017) Emerging perspectives in scaffold for tissue engineering in oral surgery. Stem Cells Int 2017: 4585401. DOI: $10.1155 / 2017 / 4585401$.

Chao A-C (2008) Preparation of porous chitosan/ GPTMS hybrid membrane and its application in affinity sorption for tyrosinase purification with Agaricus bisporus. J Membr Sci 311: 306-318.

Chatzistavrou X, Velamakanni S, DiRenzo K, Lefkelidou A, Fenno JC, Kasuga T, Boccaccini AR, Papagerakis P (2015) Designing dental composites with bioactive and bactericidal properties. Mater Sci Eng C Mater Biol Appl 52: 267-272.

Chen J, Que W, Xing Y, Lei B (2015) Fabrication of biomimetic polysiloxane-bioactive glass-chitosan hybrid monoliths with high apatite-forming bioactivity. Ceram Int 41: S393-S398.

Chiono V, Pulieri E, Vozzi G, Ciardelli G, Ahluwalia A, Giusti P (2008) Genipin-crosslinked chitosan/gelatin blends for biomedical applications. J Mater Sci Mater Med 19: 889-898.

Connell LS, Romer F, Suarez M, Valliant EM, Zhang Z, Lee PD, Smith ME, Hanna JV, Jones JR (2014) Chemical characterisation and fabrication of chitosansilica hybrid scaffolds with 3-glycidoxypropyl trimethoxysilane. J Mater Chem B 2: 668-680.

Cui L, Jia J, Guo Y, Liu Y, Zhu P (2014) Preparation and characterization of IPN hydrogels composed of chitosan and gelatin cross-linked by genipin. Carbohydr Polym 99: 31-38.

Dimida S, Barca A, Cancelli N, De Benedictis V, Raucci MG, Demitri C (2017) Effects of genipin concentration on cross-linked chitosan scaffolds for bone tissue engineering: structural characterization and evidence of biocompatibility features. Int J Polym Sci 2017: 1-8.

Dissanayaka WL, Hargreaves KM, Jin L, Samaranayake LP, Zhang C (2015) The interplay of dental pulp stem cells and endothelial cells in an injectable peptide hydrogel on angiogenesis and pulp regeneration in vivo. Tissue Eng Part A 21: 550-563.

Ducret M, Montembault A, Josse J, Pasdeloup M, Celle A, Benchrih R, Mallein-Gerin F, Alliot-Licht B, David L, Farges JC (2019) Design and characterization of a chitosan-enriched fibrin hydrogel for human dental pulp regeneration. Dent Mater 35: 523-533.

EzEldeen M, Stratis A, Coucke W, Codari M, Politis C, Jacobs R (2017) As low dose as sufficient quality: optimization of cone-beam computed tomographic scanning protocol for tooth autotransplantation planning and follow-up in children. J Endod 43: 210217.

EzEldeen M, Van Gorp G, Van Dessel J, Vandermeulen D, Jacobs R (2015) 3-dimensional analysis of regenerative endodontic treatment outcome. J Endod 41: 317-324.

Fakhri E, Eslami H, Maroufi P, Pakdel F, Taghizadeh S, Ganbarov K, Yousefi M, Tanomand A, Yousefi B, Mahmoudi S, Kafil HS (2020) Chitosan biomaterials application in dentistry. Int J Biol Macromol 162: 956-974.

Galler KM, Brandl FP, Kirchhof S, Widbiller M, Eidt A, Buchalla W, Gopferich A, Schmalz G (2018) Suitability of different natural and synthetic biomaterials for dental pulp tissue engineering. Tissue Eng Part A 24: 234-244.

Galler KM, D'Souza RN (2011) Tissue engineering approaches for regenerative dentistry. Regen Med 6: 111-124.

Galler KM, D'Souza RN, Hartgerink JD (2010) Biomaterials and their potential applications for dental tissue engineering. J Mater Chem 20: 8730-8746.

Gao L, Gan H, Meng Z, Gu R, Wu Z, Zhang L, Zhu X, Sun W, Li J, Zheng Y, Dou G (2014) Effects of genipin cross-linking of chitosan hydrogels on cellular adhesion and viability. Colloids Surf B Biointerfaces 117: 398-405.

Gathani KM, Raghavendra SS (2016) Scaffolds in regenerative endodontics: a review. Dent Res J (Isfahan) 13: 379-386.

Geris L, Lambrechts T, Carlier A, Papantoniou I (2018) The future is digital: in silico tissue engineering. Curr Opin Biomed Eng 6: 92-98.

Hamedi H, Moradi S, Hudson SM, Tonelli AE (2018) Chitosan based hydrogels and their applications for drug delivery in wound dressings: a review. Carbohydr Polym 199: 445-460.

Hilkens P, Bronckaers A, Ratajczak J, Gervois P, Wolfs E, Lambrichts I (2017) The angiogenic potential of dpscs and scaps in an in vivo model of dental pulp regeneration. Stem Cells Int 2017: 2582080. DOI: 10.1155/2017/2582080.

Hilkens P, Driesen RB, Wolfs E, Gervois P, Vangansewinkel T, Ratajczak J, Dillen Y, Bronckaers A, Lambrichts I (2016) Cryopreservation and banking of dental stem cells. Adv Exp Med Biol 951: 199-235.

Hilkens P, Gervois P, Fanton Y, Vanormelingen J, Martens W, Struys T, Politis C, Lambrichts I, Bronckaers A (2013) Effect of isolation methodology on 
stem cell properties and multilineage differentiation potential of human dental pulp stem cells. Cell Tissue Res 353: 65-78.

Huang GT, Garcia-Godoy F (2014) Missing concepts in de novo pulp regeneration. J Dent Res 93: 717-724.

Hutmacher DW (2001) Scaffold design and fabrication technologies for engineering tissues-state of the art and future perspectives. J Biomater Sci Polym Ed 12: 107-124.

Karageorgiou V, Kaplan D (2005) Porosity of 3D biomaterial scaffolds and osteogenesis. Biomaterials 26: 5474-5491.

Kassebaum NJ, Bernabe E, Dahiya M, Bhandari B, Murray CJ, Marcenes W (2014) Global burden of severe periodontitis in 1990-2010: a systematic review and meta-regression. J Dent Res 93: 1045-1053.

Kassebaum NJ, Smith AGC, Bernabe E, Fleming TD, Reynolds AE, Vos T, Murray CJL, Marcenes W, Collaborators GBDOH (2017) Global, Regional, and national prevalence, incidence, and disabilityadjusted life years for oral conditions for 195 countries, 1990-2015: a systematic analysis for the Global Burden of Diseases, Injuries, and Risk Factors. J Dent Res 96: 380-387.

Kim HY, Kim HN, Lee SJ, Song JE, Kwon SY, Chung JW, Lee D, Khang G (2017) Effect of pore sizes of PLGA scaffolds on mechanical properties and cell behaviour for nucleus pulposus regeneration in vivo. J Tissue Eng Regen Med 11: 44-57.

Klein MP, Hackenhaar CR, Lorenzoni ASG, Rodrigues RC, Costa TMH, Ninow JL, Hertz PF (2016) Chitosan crosslinked with genipin as support matrix for application in food process: support characterization and beta-D-galactosidase immobilization. Carbohydr Polym 137: 184-190.

Kokubo T, Takadama H (2006) How useful is SBF in predicting in vivo bone bioactivity? Biomaterials 27: 2907-2915.

Kumar P, Dehiya BS, Sindhu A (2017) Comparative study of chitosan and chitosan-gelatin scaffold for tissue engineering. Int Nano Lett 7: 285-290.

Kwon YS, Lim ES, Kim HM, Hwang YC, Lee KW, Min KS (2015) Genipin, a cross-linking agent, promotes odontogenic differentiation of human dental pulp cells. J Endod 41: 501-507.

Larsson L, Decker AM, Nibali L, Pilipchuk SP, Berglundh T, Giannobile WV (2016) Regenerative medicine for periodontal and peri-implant diseases. J Dent Res 95: 255-266.

Liao CT, Ho MH (2010) The fabrication of biomimetic chitosan scaffolds by using SBF treatment with different crosslinking agents. Membranes (Basel) 1: 3-12.

Liu L, Gao Q, Lu X, Zhou H (2016) In situ forming hydrogels based on chitosan for drug delivery and tissue regeneration. Asian J Pharm Sci 11: 673-683.

Liu Y-L, Su Y-H, Lai J-Y (2004) In situ crosslinking of chitosan and formation of chitosan-silica hybrid membranes with using $\gamma$-glycidoxypropyltrimetho xysilane as a crosslinking agent. Polymer 45: 68316837.

Lluch AV, Fernandez AC, Ferrer GG, Pradas MM (2009) Bioactive scaffolds mimicking natural dentin structure. J Biomed Mater Res B Appl Biomater 90: 182-194.

Manjubala I, Scheler S, Bossert J, Jandt KD (2006) Mineralisation of chitosan scaffolds with nano-apatite formation by double diffusion technique. Acta Biomater 2: 75-84.

Meschi N, EzEldeen M, Torres Garcia AE, Jacobs R, Lambrechts P (2018) A retrospective case series in regenerative endodontics: trend analysis based on clinical evaluation and 2- and 3-dimensional radiology. J Endod 44: 1517-1525.

Meschi N, Hilkens P, Van Gorp G, Strijbos O, Mavridou A, Cadenas de Llano Perula M, Lambrichts I, Verbeken E, Lambrechts P (2019) Regenerative endodontic procedures posttrauma: immunohistologic analysis of a retrospective series of failed cases. J Endod 45: 427-434.

Mi F-L, Shyu S-S, Peng C-K (2005) Characterization of ring-opening polymerization of genipin and $\mathrm{pH}$ dependent cross-linking reactions between chitosan and genipin. J Polymer Science Part A: Polymer Chemistry 43: 1985-2000.

Militký J, Bajzík V (2001) Surface roughness and fractal dimension. J Textile Institute 92: 91-113.

Murray PE, Garcia-Godoy F, Hargreaves KM (2007) Regenerative endodontics: a review of current status and a call for action. J Endod 33: 377-390.

Nakashima M, Iohara K, Murakami M, Nakamura H, Sato Y, Ariji Y, Matsushita K (2017) Pulp regeneration by transplantation of dental pulp stem cells in pulpitis: a pilot clinical study. Stem Cell Res Ther 8: 61. DOI: 10.1186/s13287-017-0506-5.

Nwe N, Furuike T, Tamura H (2009) The mechanical and biological properties of chitosan scaffolds for tissue regeneration templates are significantly enhanced by chitosan from Gongronella butleri. Materials 2: 374-398.

Petti S, Glendor U, Andersson L (2018) World traumatic dental injury prevalence and incidence, a meta-analysis-one billion living people have had traumatic dental injuries. Dent Traumatol 34: 71-86.

Ratajczak J, Hilkens P, Gervois P, Wolfs E, Jacobs R, Lambrichts I, Bronckaers A (2016) Angiogenic capacity of periodontal ligament stem cells pretreated with deferoxamine and/or fibroblast growth factor-2. PLoS One 11: e0167807. DOI: 10.1371/journal. pone.0167807.

Renard E, Amiaud J, Delbos L, Charrier C, Montembault A, Ducret M, Farges JC, David L, AlliotLicht B, Gaudin A (2020) Dental pulp inflammatory/ immune response to a chitosan-enriched fibrin hydrogel in the pulpotomised rat incisor. Eur Cell Mater 40: 74-87.

Sakai S, Kawakami K (2007) Synthesis and characterization of both ionically and enzymatically cross-linkable alginate. Acta Biomater 3: 495-501. 
Šapić IM, Bistričić L, Volovšek V, Dananić V (2014) Vibrational analysis of 3-glycidoxypropyltrimethoxysilane polymer. Macromol Symp 339: 122-129.

Schindelin J, Arganda-Carreras I, Frise E, Kaynig V, Longair M, Pietzsch T, Preibisch S, Rueden C, Saalfeld S, Schmid B, Tinevez JY, White DJ, Hartenstein V, Eliceiri K, Tomancak P, Cardona A (2012) Fiji: an open-source platform for biologicalimage analysis. Nat Methods 9: 676-682.

Sharma S, Srivastava D, Grover S, Sharma V (2014) Biomaterials in tooth tissue engineering: a review. J Clin Diagn Res 8: 309-315.

Tonda-Turo C, Gentile P, Saracino S, Chiono V, Nandagiri VK, Muzio G, Canuto RA, Ciardelli G (2011) Comparative analysis of gelatin scaffolds crosslinked by genipin and silane coupling agent. Int J Biol Macromol 49: 700-706.

Zhou X, Holsbeeks I, Impens S, Sonnaert M, Bloemen V, Luyten F, Schrooten J (2013) Noninvasive real-time monitoring by alamarBlue $((\mathrm{R}))$ during in vitro culture of three-dimensional tissue-engineered bone constructs. Tissue Eng Part C Methods 19: 720729.

Editor's note: There were no questions from reviewers for this paper, therefore there is no Discussion with Reviewers section.

The Scientific Editor responsible for this paper was Thimios Mitsiadis. 